\title{
Why worksite marketing and why now? Translating the successes from the USA to the UK
}

Received (in revised form): 11th December, 2003

\section{Vaughan Jenkins}

has over 20 years' experience in the UK financial services market, both with major financial institutions and management consultancy firms. He has held marketing roles with Prudential (UK) and NFU Mutual and was a senior manager with PriceWaterhouse and Tillinghast-Towers Perrin where he was involved in worksite marketing projects. He was also Commercial Director with Hogg Robinson, an international provider of corporate and employee services. He is now Head of Workplace Marketing with Invesco Perpetual in London.

\begin{abstract}
Worksite marketing is a term used to describe the distribution of financial services to employees via their employer. Employers facilitate access to the workforce, often via employee benefit advisers, with providers marketing voluntary (employee-funded) products and services. In the USA, payment is typically made by payroll deduction. Sales of healthcare and life assurance have grown rapidly in America in recent years, whilst in the UK, pension reform and retirement planning are forecast to make the worksite a focus for distribution in the future. Whilst there are obvious differences between the US and UK markets, especially in terms of scale, this article argues that the attractions of worksite marketing and this convergence trend can also be found in the UK. The UK market could evolve rapidly given the context of regulatory change and may outpace the USA. Traditional life and pension companies will come under threat from bancassurers and fund managers. Success in worksite marketing will require providers to overcome internal organisational design issues, implement new operating models and ensure that they have a detailed understanding of the business drivers and their impact on financial performance.
\end{abstract}

Keywords: worksite; workplace; employee benefits; voluntary benefits; distribution

Vaughan Jenkins Invesco Asset Management Ltd, 30 Finsbury Square, London EC2A 1AG, UK.

Tel: +44 (0)20 7065 3049; Fax: +44 (0)20 7065 4129; E-mail: vaughan@ caversham75.freeserve. co.uk

\section{Introduction}

The USA has seen rapid growth in the sale of employee-paid, non-pension financial services in the last few years. The US worksite marketing scene is evolving and the boundaries between corporate and retail, pension and other savings are becoming increasingly blurred. Whilst there are obvious differences between the US and UK markets, especially in terms of scale, the attractions of worksite marketing and this convergence trend can also be found in the UK. Employers in the USA and UK have been keen to control benefits costs, encouraging employees to be more self-sufficient and self-directed. Large companies in particular are supporting this move by providing electronic tools to support employees in their decision-making. The growth in voluntary (employee-paid) benefits has created an attractive market for providers. In the UK, changes in the pensions and 
tax regimes may provide a dramatic boost to worksite marketing activity, especially in the context of government support for an improved savings culture. The UK market could evolve rapidly and outpace the USA. Inevitably, some firms will adapt better than others to the new environment and some traditionally strong players, such as life companies, may be under threat from bancassurers and fund managers. Success in worksite marketing will require providers to overcome internal organisational design issues, implement new operating models and ensure that they have a detailed understanding of the business economics. Accurate customer and market segmentation will drive performance and enable providers to manage the key sensitivities.

\section{Worksite marketing}

Whilst employer-based distribution has been debated here as a means of closing the perceived savings gap, the US market has already experienced a rapid expansion in sales of non-pension products via the worksite. Evolutionary trends suggest that the next generation of worksite marketing will blur the traditional divide between retirement schemes and other individual financial planning whilst the employer as a distribution channel grows in importance. The UK could lead the way, however, as the character and economics of worksite distribution are transformed by the proposed reform of pensions and tax rules. Combined with an encouraging political and economic climate, could this be the time for the worksite to become a major buying route for consumers on this side of the Atlantic?

In the last couple of years, the potential for employer-based distribution of goods and services and especially retail financial services has generated increasing interest in both the USA and the UK. While much talked about in the UK among providers, employers and the government, in the USA, worksite or workplace marketing of voluntary, individual financial services dates back to at least the late 1940s. Over the last five years, premium income from worksite marketing, excluding pensions, has grown by 100 per cent with some $\$ 4$ bn in new business revenue in $2002 .{ }^{1}$ With five consecutive years of double-digit growth (and some players experiencing up to a 70 per cent increase in business), ${ }^{1}$ worksite marketing has clearly become a significant distribution channel for providers and a preferred buying process for employees. But even there the concept and practice of this form of distribution is set to change significantly in the next few years. In this paper, the lessons to be learned from the US experience are considered and some forecasts offered as to how UK and US worksite marketing may evolve and share similar characteristics in the future.

\section{Worksite marketing defined}

On both sides of the Atlantic, it is clear that a variety of definitions of worksite marketing are in use. This may simply reflect the particular viewpoint of commentators and participants but it also tends to show that the approach to the workplace market is in a state of flux. In the USA, worksite marketing remains quite distinct and separate from the pensions market, which has its own providers, intermediaries and buying processes.

In the USA, worksite marketing is often defined as the distribution of non-pension financial products, paid for by employees, but facilitated and endorsed by the employer. These are discretionary or voluntary selections made by individuals without any 
employer contribution and historically consisted of products and services that were individually (rather than group or employer) rated. As discussed later, the distinction between group and individual business has become much fuzzier in recent times. In fact, the range of financial services under this heading could be very wide - from car insurance to mutual funds and health cover to (more recently) banking products. An important feature of the proposition to employees is that payments are made automatically through payroll deductions. This convenience factor is a major part of the appeal of worksite marketing in the USA. In the absence of a direct debit system as known in the UK, this form of premium collection is efficient for provider and employee alike, although inevitably continuation problems can arise when an employee changes jobs.

\section{The evolution of worksite marketing}

The appeal of worksite marketing to insurance providers is easily understood.

The cost-effectiveness of collective selling combined with the endorsement of an employer can look particularly attractive compared to cold-calling sales alternatives. Historically, worksite marketing in the USA tended to be aimed at small to mid-sized firms whose benefit packages tended to be sparse.

Brokers and insurance agents could offer voluntary plans at no cost to the employer in return for access to the employee-base, typically using seminars as the primary promotional method. Employees would often be enrolled on the spot, sometimes through 'assertive' sales tactics. Worksite marketing in the USA evolved into a distribution channel primarily focused on the volume 'blue-collar' market segments but its image became tarnished through association with high-cost, poor value products, particularly some universal whole-of-life contracts. Although sales processes remained less regulated than the UK, the labour-intensive sales methods required high margins to remain economic. Some firms became highly successful by offering a very limited product range, most notably American Family Life Assurance Company (AFLAC). Now with some 39,000 agents, AFLAC focused on insurance cover in the event of cancer and was very successful with its direct sales model aimed at the small corporate market. In recent years its product range has expanded to other health and disability plans and it has expanded overseas, most notably into the Japanese market.

In the USA, however, there has been a significant blurring of the lines between group and individual voluntary products. Eastbridge Consulting Group estimate that in 2002, voluntary group life and health sales via the worksite accounted for 42 per cent of market revenues whilst 58 per cent of all individual sales were via the worksite. The underlying trend has been strongly in favour of group products but providers are increasingly offering defined contribution, hybrid products that defy traditional distinctions.

As the retail financial services market became more competitive in the 1990s, so firms looked for new efficiencies in distribution. Successful transformation has been achieved by taking a fresh look at the elements of the value chain and the application of new technologies, particularly the internet. Some insurers have focused on product manufacture and have outsourced the worksite sales function to specialist firms or 'independent' agents that 'merchandise' products and enrol employees in benefit programmes on their behalf. Many US 
life offices continue to operate worksite marketing simply as an extension of their agency management arms.

Whilst much of the recruitment and enrolment process continues to be conducted face-to-face and is paper-based, the trend is towards a multi-channel approach including web-based sign-up. Functionality offered via intranet or extranet has become increasingly sophisticated, as providers and intermediaries have added a variety of financial planning tools and consumer education facilities, although again within a markedly different compliance regime to that of the UK. Web technology has also shifted the point of sale from just the place of work to the home or other internet access point and from the employee alone to their wider family unit.

As in the UK, the benefit packages offered by larger employers, both voluntary and core (such as 401-k retirement schemes), are often designed and recommended to employers by the large employee benefit consultancies (EBCs). Their focus is naturally on the design and administration aspects of benefits, whether in flexible plans or more traditional arrangements. Content providers, such as insurance companies, are typically screened by EBCs and have often been held at arm's length from the corporate client. EBCs have extensive employee communication businesses, including intranet design but have lacked the manpower to deliver face-to-face services, particularly in relation to pro-active enrolment. As in the UK, employers and EBCs have often been content to give this potentially labour intensive element over to insurers or broker sales forces, especially in the case of voluntary benefit plans where suppliers clearly have a vested interest in pro-active promotion.

\section{Worksite marketing - The buyer perspective}

In the 2003 MetLife Study of (US)

Employee Benefit Trends, ${ }^{2}$ some 55 per cent of employees saw payroll deduction as the key advantage of voluntary benefit plans offered by employers with 51 per cent citing the convenience over retail purchasing. Forty-three per cent also felt that these programmes helped them to be more disciplined in how they saved.

Employers meanwhile focused on staff retention and cost control as the most important benefit objectives (54 per cent). Forty-three per cent saw benefits to help the work-life balance as the most important employee benefit strategy whilst providing employee decision support tools was seen as the key strategy by 29 per cent of respondents. Employer attitude to benefits is obviously very influential on worksite marketing results and US employees are familiar with the trend towards shifting responsibility (aka cost and risk) from the employer to them. Defined contribution pension schemes arrived early in the USA and the current focus is on reducing the spiralling costs of medical expense insurance by changing benefits and funding arrangements. Some of the surge in worksite sales is directly attributable to employees having to buy back their benefits on a voluntary basis.

In an economic downturn, CFOs have played a key role in questioning the value to the organisation of the benefit plans they provide, forcing human resources management to reassess and justify their strategies. For some organisations cost reduction has been of over-riding importance but many have highlighted the fact that employees are often ill-prepared to take on financial decisions for themselves. The MetLife Study, and many others in the USA and UK, indicate significant gaps in the financial education of employees and the 
provisions they have made for their future. Not only do employees feel that their employers could do more to help inform them but often they feel that it is the employers' obligation to do so.

Communication and access to advice are common themes in the USA and UK as the means to effecting change in the employee benefits market.

Given the fact that the USA moved some time ago towards defined contribution pension schemes, creating a $\$ 2$ trn $401-\mathrm{k}$ pension market alone, it might be imagined that employee communication and support is a fine art there. This view is true to an extent but one needs to take account of the fact that around 20 per cent of the investments in 401-k plans consist of stock in the firm the employee works for, a point alarmingly highlighted in the post-Enron and WorldCom environment. Research by Mutual of Omaha in $2002^{3}$ also found that employees were spending less than ten hours a year on average managing their retirement funds with 9 per cent spending no time at all on financial planning. The MetLife Study referred to previously also found the median average time employees spent on making benefit decisions was just 32 minutes per year! ${ }^{2}$

The challenge of employee engagement in financial planning is at least as great in the USA as here and is exacerbated by the historic structure and practice of financial service providers. The separate pension, core group benefit and voluntary benefit silos create not only a fragmented distribution landscape but also an incoherent and incomplete employee proposition. Consumers will increasingly seek a simplified but comprehensive view of their financial position and options, both employer-paid and voluntary. This is one factor that is going to drive greater consolidation and collaboration on the supply side. The worksite is already en route to becoming a predominantly retail environment and employees will ultimately force providers to revamp their organisational designs and product centric approaches. Intermediaries have no room for complacency and some have begun to adapt themselves both here and in the USA into new service lines. While the USA is engaged in a process of integration and cooperation to deliver a new style of comprehensive worksite marketing propositions, the UK may undergo a more revolutionary change in relation to worksite marketing. This may go a long way to compensate for the much smaller scale of the UK labour market compared to its US cousin.

\section{Distant cousins?}

In terms of the profile of their labour markets, the USA and UK show some marked differences, the greatest of which is the relative scale of the two. As Table 1 below shows, ${ }^{4}$ the USA has five times more employers in total and significantly more large corporate employers.

Geography also provides some contrasts - the distance from Los Angeles to New York being about the same as the distance from London to Dakar in West Africa. Of course, other differences abound in terms of regulation, culture, language and demographic profiles and yet, despite all of these differences, there are many common factors that make comparison worthwhile regarding employer-based distribution of financial services. These similarities include:

- comparable average wages;

- a high concentration of workers in service industries;

- a growing use of technology in employee communication; 
Table 1: Economies of scale favour worksite marketing in the USA

\begin{tabular}{ll}
\hline US market & UK market \\
\hline 134 million employees & 23 million employees \\
21 million firms & 3.8 million firms \\
c. 1000 firms employ over 10,000 staff & 44 firms have over 5,000 staff \\
c. 8,500 firms employ over 1,000 staff & c. 1,300 firms employ over 1,000 staff \\
c. 16,000 employ over 500 staff & c. 2,600 employ over 500 staff \\
Average salary $\$ 38,000(€ 41,000)$ & Average salary $£ 24,000(€ 38,000)$ \\
\hline
\end{tabular}

- common issues in relation to retirement benefit provision and state funding;

— demand for financial education amongst employees;

- the employer remains generally well-regarded by employees as a source of impartial information and as a conduit to reliable financial advice.

\section{Worksite marketing - British fashion}

In the UK, however, the US-style of worksite marketing, particularly of savings and investment products, is still in its infancy. For many product providers in the UK, worksite marketing is more of a wholesaling than a retailing concept, despite the theoretical opportunities that exist to offer improved propositions to employees. Here, those focused on group schemes and occupational pensions in particular, often see worksite marketing as the employee communication end of a sales process that is primarily focused on the employer and/or trustees as the buyer. Within this definition of worksite marketing, the employer is wholly, or at least jointly, funding benefits. Having won through a tendering process and installed a scheme arrangement, worksite marketing has been seen as no more than the process of recruiting or transferring in members and their contributions. Communications are geared towards joining and the provider's motivation is to accumulate assets (or units of risk in the case of protection plans) under management as quickly as possible. This is little different to the present US pensions market.

Benefit schemes sold on a group basis, business to business, but where employees purchase the benefit, are also familiar. The employer (and their advisers) may have secured attractive terms for employees on a 'bulk' basis and may even subsidise rates but the employees' selection of benefits is voluntary. Flexible benefit arrangements would fall into this category, along with plans devised to accommodate otherwise non-qualifying employees, eg in the UK, those too young to join a final salary pension scheme are offered a group personal pension (GPP) alternative.

As we have seen, worksite marketing in the USA is almost synonymous with the payroll deduction of regular premiums and it is a market where high penetration levels of small but frequent sums are required to be economical. Driving volume in this small case size, monthly payment market is an engrained view of what worksite marketing is about and it is one to be found in the UK.

As an alternative route to market, several UK banks, insurance companies and investment firms have been active for some time, either directly or via intermediaries. Personal lines insurance, especially motor cover, unsecured loans and mortgages and other simple products capable of being direct marketed to 
employees have been on offer via the employer gateway for several years, especially in the case of large employers. Many providers, especially general insurance providers, have seen this form of distribution as being a variant of their other affinity group marketing activities. It is also a percentages game where success or failure is geared to the volume of individuals taking up and maintaining regular payments on products with margins that are acutely sensitive to acquisition costs. Product pushing rather than needs-based analysis naturally follows, as the aim is to recruit as many customers as cheaply as possible. This style of enrolment is also very characteristic of the US worksite market where enrollers use (at most) a rudimentary needs analysis approach.

\section{All change}

The recent surge in interest here, however, has much to do with pension reform leading not only to changes in retirement planning but also personal financial habits in general. Certainly, employee demand for financial advice is converging with the government's public policy objectives in relation to savings and investment markets; the employers' need to control the cost of benefit provision and the product providers' need to secure economical distribution channels in the face of reduced margins. It is this unusual confluence of interests that creates the conditions for a lift-off in worksite marketing in the UK but the potentially explosive impact of the demise of occupational pensions in favour of personal and stakeholder arrangements on worksite marketing economics appears to be far less widely appreciated. If there is an enormous multi-billion pound shift in money from the institutional to the retail market, then that in turn would see worksite marketing being based on (but not restricted to) large lump sum pension transfer business. The impact on worksite distribution economics would be enormous and so too could be the transformation in the services delivered to employers and employees.

The introduction of so-called second-tier advisers has been seen as a critical factor in worksite marketing becoming viable in the UK. Whilst a simplified sales process would clearly benefit firms only selling regular premium products or small case size lump sum investments, substantial transfers into stakeholder pensions from occupational schemes would fund (and/or cross-subsidise) investment in marketing, customer services and the acquisition costs of other products under the current regulatory regime. Whilst the Pensions Green Paper may have been criticised for failing to address the situation for those with inadequate (or non-existent) pension provision, it could have a major impact on current pension funds and retirement choices, particularly taking into account proposed tax changes. These changes and proposed changes in taxation rules are already having an effect well before April 2005 as the lifetime limit is considered and the potential for annual vesting, etc. The effect is also right across the spectrum of employers and employees from executives in FTSE companies to the self-employed business owner, creating worksite marketing potential in many different market segments.

\section{Winners and losers}

In the US market, there have been some exits from the worksite marketing arena, most notably Prudential US. Some firms have been taken over, some by European firms such as Aegon and ING. Some were slow to adapt to the use of the 
internet and call centres to reduce distribution costs and improve coverage, whilst others have failed to secure access to corporate clients either directly or via intermediaries. Further consolidation of suppliers is expected despite the rise in worksite sales. It also seems inevitable that pensions marketing will become intertwined with the provision of other benefits. This could result in too much capacity chasing too little distribution resource, as new operating models relying on remote distribution methods have still to mature. As in the UK, US consumers/employees often prefer face-to-face contact when making important financial decisions. At the same time, regulatory change has introduced the bancassurance model to the USA, both attracting distribution capacity and custom away from the worksite. There is every reason to believe, however, that the US worksite scene will continue to see double-digit growth for some time to come as employee demand and employer support is tapped with more effective and efficient sales tools and techniques, such as interactive financial planning models and personalised marketing approaches.

Whilst the history and current challenges may be a little different to the UK, the attractions of worksite marketing and the key ingredients for success are very similar. What is changing is the capability for some (but perhaps only a small number) of UK providers to develop worksite marketing as a significant alternative distribution channel. Some life offices may be able to translate their strengths in occupational pensions into the 'retail' arena but they face significant competition from fund management firms and retail banks. If banks and fund managers form alliances to offer a breadth of services, superior investment performance and legacy free customer service then it is possible to imagine life offices being marginalised. Life offices, composite insurers and banks have significant organisational design and political factors to overcome and, as seen in the USA, one of the greatest barriers to worksite marketing success is the internal division within firms between retail and corporate business.

In the proposed pensions reforms, however, UK firms have a rare opportunity to tap the employer/ employee market. For those that adapt and thrive, we can expect to see a number of changes in the worksite market that might include:

- new business models that can exploit the demise of occupational pensions through products, services and sales methods supported by access to financial advice. Regulated advice may be increasingly supplanted by information and (self-) guided sales processes;

- a greater focus on holistic financial planning and overall asset allocation rather than separate pension and savings 'pots'. In and at retirement planning will create new market opportunities and new winners and losers amongst providers;

- collaboration between providers and multi-tied agents to produce attractive propositions to employers, possibly at the expense of some resourceconstrained independent financial advisors (IFAs);

- the introduction of stakeholder-style savings plans with a simplified sales process that transform the economics of low case size single and regular premium sales, coupled with lower cost enrollers;

- web access and comfort with on-line purchasing continuing to improve, whilst providers demonstrate their experience in customer relationship management systems and 
personalisation tools, engaging employees and improving the quality of the customer experience;

- EBCs and corporate IFAs changing their roles with large employers, while providers strengthen direct relationships with employers and employees;

- flexible benefit schemes are used as vehicles for financial products and advice — bulk arrangements with individual election. Providers might be tempted to ally with or displace EBCs in order to offer flex packages direct to employers;

- the small and medium-sized enterprise market remains largely untapped for individual sales, with IFAs having focused on group schemes and director-level financial planning creating the potential for new, more cost-effective direct sales forces;

- the government and the Financial Services Authority (FSA) act upon their recognition of the worksite as a means to closing the savings gap and introduce employer incentives, educational support and rule changes to facilitate employee action and self-provision.

Set against this array of opportunities there are of course a number of issues which providers on both sides of the Atlantic have to contend with, such as:

- the fact that providers are only too well aware that take-up rates on corporate pension schemes, even those with attractive employer contributions, can be stubbornly low. How much more difficult will it be to attract and convert employees in relation to self-funded, voluntary savings and investments? Whilst seminar-based selling can work well in relation to event-related financial planning, eg pre-retirement counselling, is this cost-effective for more broadly-based worksite marketing?

- even in the USA, questions have been raised over the cost-effectiveness of investments in web technology due to low usage rates. MetLife have suggested that schemes of less than 10,000 employees are uneconomical for this communication medium - a level which would rule out all but a handful of UK private sector firms;

- to secure access to large employee bases, will providers be forced to offer 'better than High Street' prices to employees? Clearly, if the market is commoditised too far the channel will lose its appeal compared to alternative distribution channels. The provider's value proposition will need to compete on something other than price through the provision of a broad range of products (perhaps in-house and gap-filled), excellence in execution through an integrated multi-channel approach and differentiated tools and facilities;

- if the provider already provides services - whether a pension or general insurance scheme - does this help or hinder the move to provide additional voluntary benefits? Will EBCs and employers combine to resist too much commitment to a single provider?

- how will relationships with EBCs and IFAs develop? Placing a bet on direct distribution may well undermine important sources of existing business and what if worksite volumes are below or later than expected?

— it seems clear that any bet on worksite marketing needs to be informed by a robust segmentation process. The worksite channel is especially complex given the number of variables involved - the employer profile; employee characteristics and 
behaviours; intermediaries and possibly collaborative partners in terms of product provision and administration. This amounts to a significant number of moving parts, which need to be well coordinated to operate effectively.

While the size of the prize for successful worksite marketing is significant, the threats and uncertainties are such that there are important benefits to be gained from trying to model some potential outcomes. While US and other overseas experience, eg Eire, can provide some useful proxies for assumptions, an important part of a worksite marketing approach is often much closer to home - a thorough understanding of the current expense base, the fixed, variable and truly marginal components and their behaviour in relation to different scenarios. Work in this field to date underscores the importance of understanding and calibrating the key sensitivities to inform decisions on targeting clients, pricing and product offerings, collaborating with third parties and sales processes.

With both the UK and US markets on the cusp of significant change, the greater future opportunities may lie over here due to the changes in the pensions market rather than the voluntary benefits market alone. Of course, if hundreds of billions of pounds do begin to flow into individual wealth funds in the UK market, this could well spark interest amongst new entrants from the USA armed with worksite expertise!

\section{References}

1 Eastbridge Consulting, 4th Annual US Worksite study, June 2003. (Figures cover 1997-2002 inclusive.)

22003 MetLife Study of (US) Employee Benefit Trends, December 2003. Available via www.metlife.com.

3 '401(k) Plan Preferences Study', December 2002. Telephone survey completed by Weise Research Associates Inc. on behalf of Mutual of Omaha.

5 Sources: US government labor statistics 2002 and UK government statistics 2002 . 